\title{
UNSUPERVISED METHODOLOGY TO IN-SEASON MAPPING OF SUMMER CROPS IN URUGUAY WITH MODIS EVI'S TEMPORAL SERIES AND MACHINE LEARNING.
}

\author{
Adrián Cal, Guadalupe Tiscornia \\ Unidad de Agroclima y Sistemas de Información (GRAS), Instituto Nacional de Investigación Agropecuaria (INIA), Uruguay - \\ (acal, gtiscornia)@inia.org.uy
}

KEY WORDS: Crop mapping, elbow method, EVI, k-means, smoothing spline, time-series, unsupervised.

\begin{abstract}
:
This paper presents a new methodology for mapping summer crops in Uruguay, during the season, based on time-series analysis of the EVI vegetation index derived from the MODIS sensor. Time-series were processed with the k-means unsupervised machine learning algorithm. For this algorithm, the ideal number of clusters was estimated using the elbow method. Once the clusters were obtained, for each one, the average phenological signature was adjusted using a nonlinear smoothing spline regression technique. Additionally, using the derivative analysis, the key points of the curve were estimated (minimum, maximum and inflection points). When analyzing the average signature of each cluster, those whose signature follows the seasonal pattern of an agricultural crop (similar to a Gaussian function) were selected to generate a binary map of crops/non-crops. The estimated crop area is 2,336,525 hectares, higher than the official statistics of 1,667,400 hectares for the 2014-15 season. This overestimation can be explained by the resolution of the MODIS pixel (250 meters), where each has a different degree of purity; and commission errors. The methodology was validated with 5,317 ground truth points, with a general accuracy of $95.8 \%$, kappa index of 85.6, production and user accuracy of $85.1 \%$ and $91.3 \%$ for crops/non-crops.
\end{abstract}

\section{INTRODUCTION}

Uruguay has a total area of 176,220 square kilometers (FAO, 2019). According to national statistics for the 2014-15 season, the area for summer agricultural crops (rice, corn, and soybean) was 1,667,400 hectares $(16,674 \mathrm{~km} 2)$ (MGAP-DIEA, 2016). The summer crops area has increased from 300,000 hectares in 200001 to $1,400,000$ in 2012-13 (MGAP-DIEA, 2005). This growth is explained by the expansion of soybean crop area determined by the international prices of this commodity that went from 200 dollars a ton in 2000 to 700 in 2012 (World Bank, 2019). This process of expansion of the agricultural area also occurred in other countries of the region such as Argentina, Brazil, and Paraguay (Llonch, 2019). Considering the most important crops in Uruguay: soybean, rice, and corn, the area occupied by these in 2014-2015 were of 1,334,000, 160,700, and 83,200 hectares respectively (MGAP-DIEA, 2016), Considering these same crops but in yield production, soybean represents 3,109,300 tons, rice, 1,348,300 tons and corn, 479,500 tons. About agricultural exports for 2017, soy and rice represented 1189 and 448 million dollars (URUGUAY XXI, 2018).

Taking into consideration agriculture importance for the Uruguayan economy, it is central to have a tool that allows mapping agriculture areas during the season, to assess their status, through vegetation indexes like the Normalized Difference Vegetation Index (NDVI) or Enhanced Vegetation Index (EVI) (NASA-Earth Observatory, 2000). This tool will support decision-making of different stakeholders, such as farmers, technical advisors, and government agencies related to agriculture.

For mapping agriculture areas, classic methods use ground truth points to train supervised models of machine learning. In Australia, supervised techniques were tested on MODIS multitemporal images with time series harmonic analysis (HANTS) and principal component analysis (PCA) (Potgieter, Apan, Hammer, \& Dunn, 2005). Other methods, combined time-series of MODIS, Landsat 8 and Spot 4 images, using support vector machines (SVM) to mapped different land uses and land covers
(Waldner, Canto, \& Defourny, 2015). In Brazil, using random forest, some authors classified land uses with time-series of EVI of Landsat 8 smoothed with double logistic function (Bendini et al., 2016).

Unsupervised classification techniques have also been tested by segmenting Spot 4 and 5 images into different land use and land cover categories, using k-means with Pearson Systems (Rekik, Zribi, Hamida, \& Benjelloun, 2009).

In this paper, we proposed a new methodology to map agricultural crops without ground truth data and during the growing season, analyzing time-series of a vegetation index, with machine learning techniques such as unsupervised classification, nonlinear interpolation techniques, derivative analysis and expert knowledge.

\section{MATERIALS AND METHODS}

We considered Uruguay as the study, between latitudes 30 and 35 south, and longitudes 53 and 59 (Figure 1).

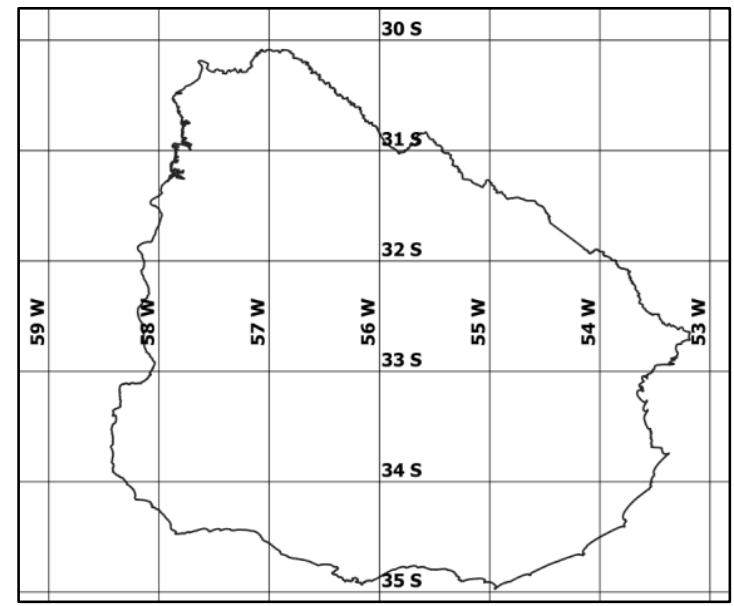

Figure 1. Uruguay. 


\subsection{Hardware and software}

The processing was performed on a computer with an INTEL CORE i7 processor of $2.90 \mathrm{GHz}$ and 4 cores, $24 \mathrm{~GB}$ of RAM, 1 TB solid-state disk and 64-bit Windows 10 operating system. The scripts were developed in the statistical software R, version 3.5.0 and the RStudio IDE version 1.1.453.

\subsection{Satellite imagery}

For mapping agricultural areas during the season, satellite images from the MOD13Q1 version 6 product (Fontana et al., 2015) of the Moderate Resolution Imaging Spectroradiometer (MODIS) onboard the NASA TERRA satellite were used (Salomonson, Barnes, \& Masuoka, 2006). This satellite has a daily review period. The MOD13Q1 has 2 bands of the vegetation indexes: EVI and NDVI, with a pixel spatial resolution of 250 meters. This product is a synthetic image where the value of each pixel is the highest from daily images of a 16-day period. For Uruguay, tile h13v12 was used, which covers the entire country (Figure 2). Images corresponding to the 2014-15 summer season (from September to March) were selected.

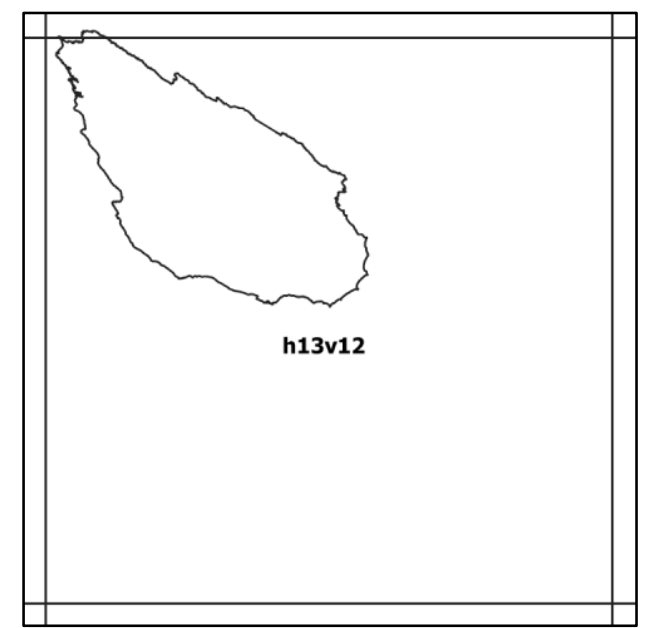

Figure 2. MODIS sinusoidal tile grid h13v12.

\subsection{Methodology}

Time-series of EVI index were analyzed for each pixel during the growing season (from September to March) of summer crops (soybean, corn, and rice). EVI was used, since some studies have shown that it does not saturate at high biomass values as it happens with NDVI (Huete et al., 2002).

Each land use and land cover (LULC) has a different evolution of EVI during an agricultural year, which represents its growth and development cycle, known as a phenological signature (Chatziantoniou, Psomiadis, \& Petropoulos, 2017). We classify LULC in different categories such as grassland, implanted forests, natural forests, crops, water bodies, wetlands, or others such as urban areas.

We hypothesize that it is possible, by combining machine learning techniques such as unsupervised classification, smoothing spline nonlinear regression, derivative analysis, and expert knowledge, to separate pixels from the same category. In addition, since each LULC has its specific phenological signature, it would be possible to separate the agricultural crops signature from the rest. Characteristics phenological signatures for different LULC in Uruguay are shown in Figure 3. Summer crops signature has a shape similar to a Gaussian function, the same pattern observed by other authors (Johnson, 2010) (Wardlow \& Egbert, 2010).

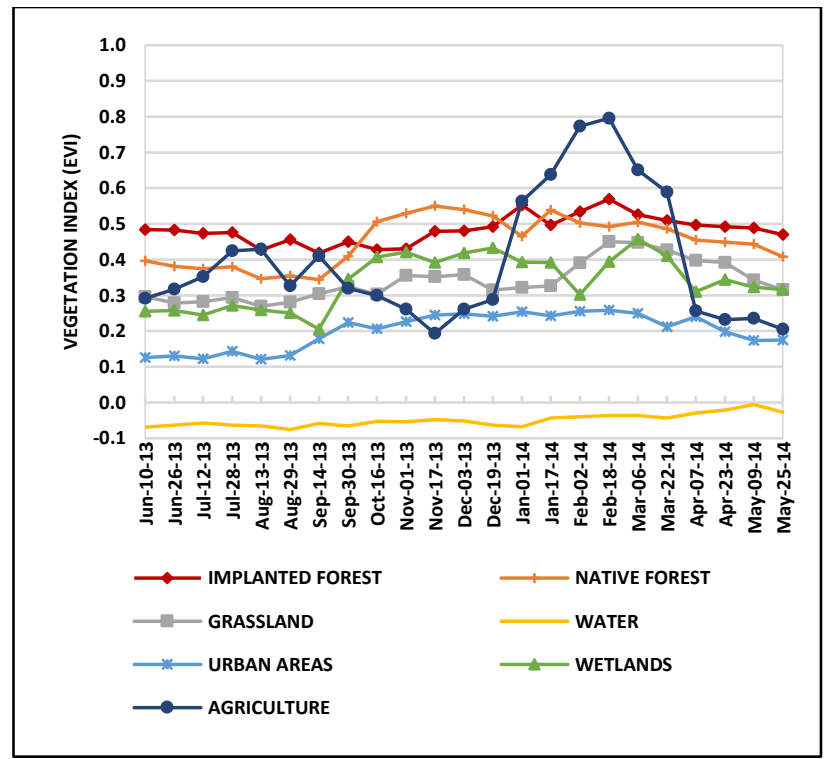

Figure 3. Characteristic phenological signatures of different land use and land covers in Uruguay.

\subsection{Workflow}

2.4.1 Imagery stacking: The first step was the creation of the image stack to analyze the EVI time series of each pixel. In Uruguay, the sowing of summer crops is carried out from October until December. In this context, to identify summer crops, an image stack from September to the beginning of March of the following year (September 2014 to March 2015) was set (Figure 4). In the stack, the images are organized in chronological order, the first being the oldest and the last, the most current. This stack is a multi-band file of 12 images in GeoTIFF format, where each band corresponds to a MODIS image (Table 1). The multiband stack is masked by a layer of Uruguay to use only the pixels that are within Uruguayan continental territory.

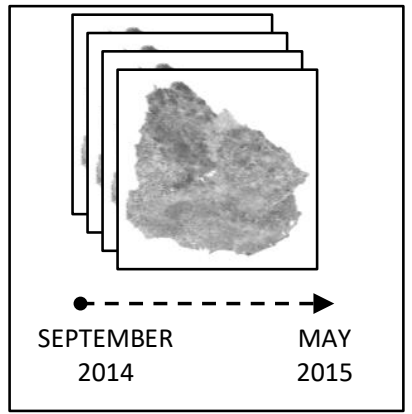

Figure 4. EVI MODIS stack for crop mapping. 


\begin{tabular}{|c|c|c|}
\hline $\begin{array}{c}\text { MOD13Q1 } \\
\text { IMAGE }\end{array}$ & DATES & YEAR \\
\hline 241 & August 29 to September 13 & 2014 \\
\hline 257 & September 14 to September 29 & 2014 \\
\hline 273 & Sempteber 30 to October 15 & 2014 \\
\hline 289 & October 16 to October 31 & 2014 \\
\hline 305 & November 1 to November 16 & 2014 \\
\hline 321 & November 17 to December 2 & 2014 \\
\hline 337 & December 3 to December 18 & 2014 \\
\hline 353 & December 19 to January 3 & 2014 \\
\hline 001 & January 1 to January 16 & 2015 \\
\hline 017 & January 17 to February 1 & 2015 \\
\hline 033 & February 2 to February 17 & 2015 \\
\hline 049 & February 18 to March 5 & 2015 \\
\hline
\end{tabular}

Table 1. MODIS image stack dates.

2.4.2 Time-series clustering: The next step is to do an unsupervised classification using a k-means algorithm. The objective of the k-means algorithm is to group the elements of a set of data into different classes, without using labeled data, where the elements of each class are more similar to each other than to the rest of the groups. This grouping is based on a similarity metric, such as Euclidean distance, applied to the variables in a dataset (Jain, 2010). The algorithm is executed in the EVI images stack, where each image corresponds to a date. Each image of each date is a variable of the entire dataset.

A very important part of the application of the k-means algorithm is the determination of the number of clusters to be use. There are different methodologies (elbow method, gap, silhouette) to decide the ideal number of classes and, for computational efficiency, the elbow method was used (Kodinariya \& Makwana, 2013). We executed the k-means in the stack 40 times and, in each execution, use a number $\mathrm{k}=1$ to 40 . After that, for each run, the within-cluster sum of squares (WCSS) is calculated, and the WCSS graph vs. the number of clusters is generated. The optimal number of clusters is determined by identifying the elbow of the curve: the point with the greatest orthogonal distance to the straight line that joins the first and last point of the curve.

2.4.3 Smoothing spline: Once the optimal number of clusters was defined, the clustering corresponding to that $\mathrm{k}$ value was selected. For that clustering, the smoothed average signature was generated, for each cluster, using the smoothing spline method (Pollock, 1999). This technique allows reconstructing the original signature with daily EVI values. After that, the first derivative of the smoothed signature is calculated and the key values of the curve are obtained: minimums, maximums, and inflection points.

2.4.4 Cluster selection: The next step was to generate the graphics for each cluster, with: the individual signature of pixels belonging to that cluster; the smoothed average signature; and the key points of the curve (minimums, maximums, and inflection points). The average signatures, together with the 5th and 95th percentile lines of each cluster, are visually analyzed to find those that follow the pattern of an agricultural crop. When crop clusters have been identified, the binary map of crops/non-crops is generated.
2.4.5 Validation: To validate the methodology 5,317 ground truth points of crop/non-crop collected during summer 2014-15 were used (Figure 5), and a confusion matrix was constructed. Different metrics were calculated: overall accuracy, balanced accuracy, kappa index, user's accuracy, producer's accuracy, and f-measure.

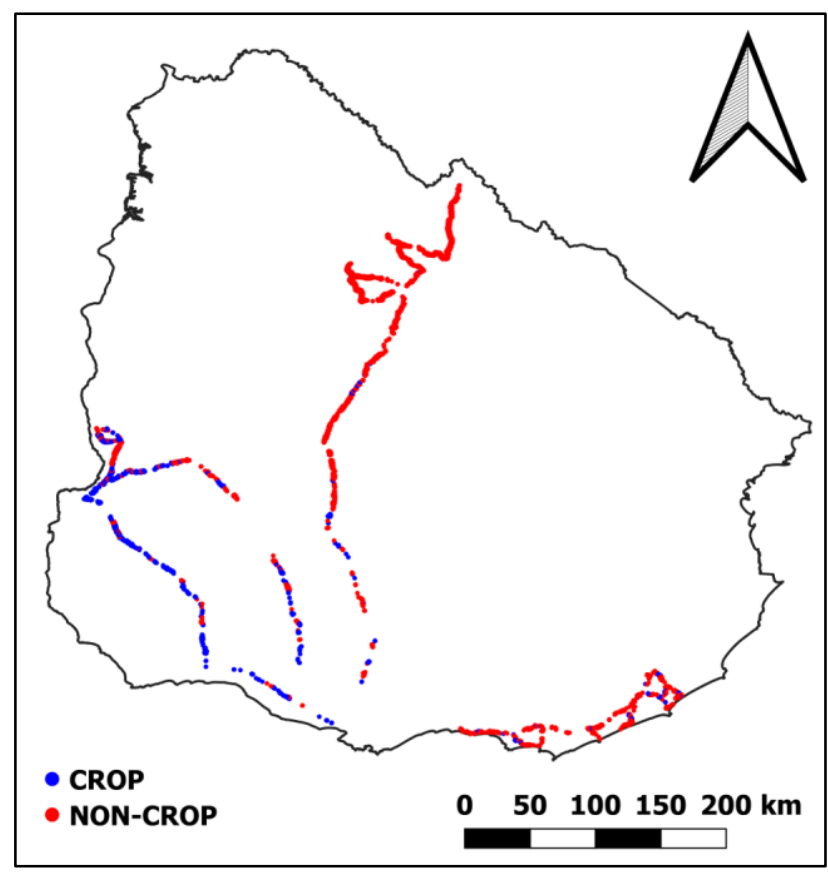

Figure 5. Ground truth points of crop/non-crop.

A diagram of the process described above and the different steps of the workflow for mapping agriculture areas is shown in Figure 6.

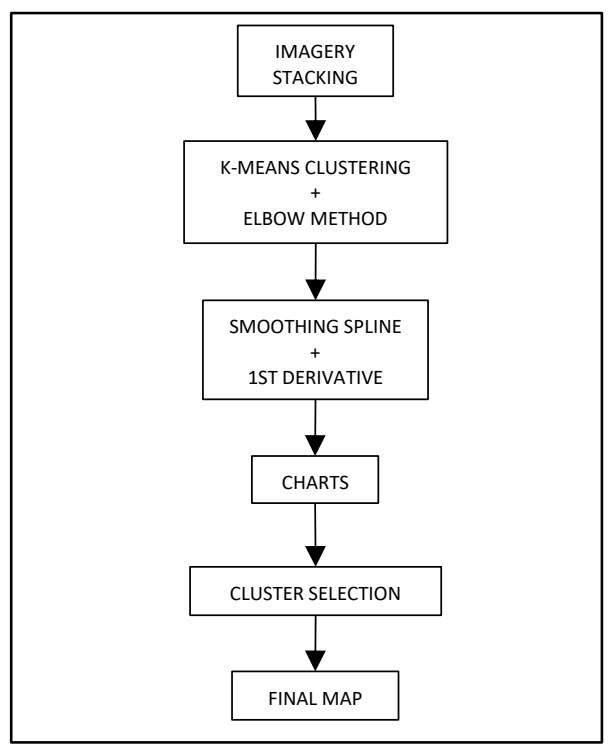

Figure 6. Workflow for mapping agricultural areas.

\section{RESULTS AND DISCUSSION}

The k-means algorithm with values of $\mathrm{k}$ from 1 to 40 was executed. Each run of $\mathrm{k}$ clusters was made with a threshold value of 0.95 and a maximum of 300 iterations. For each execution, the WCSS was calculated (Figure 7, WCSS against the number of clusters $\mathrm{k}$ used in each run). When the number of clusters used by 
the k-means algorithm increases, the WCSS rapidly decays from almost $28 \times 10^{8}(\mathrm{k}=1)$ to a value greater than $10 \times 10^{8}(\mathrm{k}=14)$, and, from 14 clusters or more, it stabilizes and becomes asymptotic below the $10 \times 10^{8}$ value. This figure shows the optimal number of clusters to be used, which corresponds to the bend of the curve (elbow). This point of the curve is the one with the greatest orthogonal distance to the straight line that joins points 1 and 40 of the curve (optimal number of clusters $=9$ ).

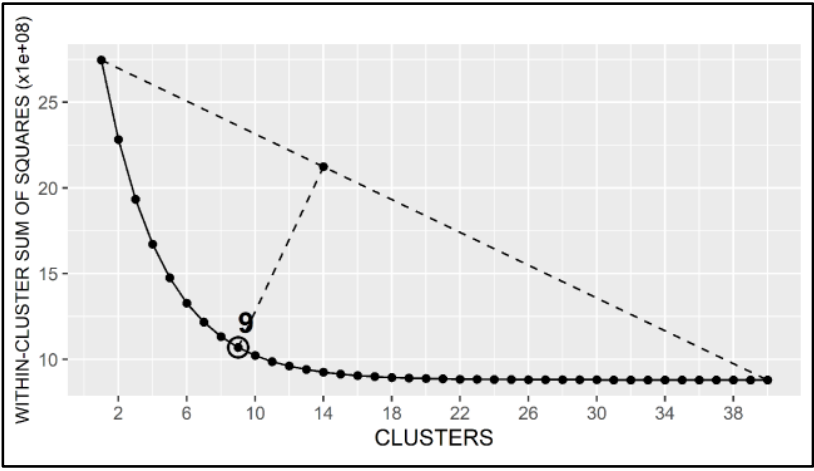

Figure 7. Optimal number of clusters determination with elbow method.

Once the optimal number of clusters was defined, for the clustering corresponding to that $\mathrm{k}$ value, each cluster was analyzed. We first generate the average signature of the cluster: the average EVI value for each date of the time series was calculated, and then, from those data and by nonlinear interpolation with the smoothing spline method, the average signature was estimated on a daily-basis (Figure 8). Also, for each date, the values corresponding to the 5 th and 95 th percentile were estimated, and the daily step curves of those percentiles were also constructed by the smoothing spline method. For the average signature, the first derivative was calculated, and minimum, maximum and inflection points of the curve were determined (Figures 9 to 12 show some examples). The unprocessed time series of each pixel that belong to the cluster are included in the graphics. With many pixels belonging to each cluster, individual signatures overlap and look like a black band. A raster was generated, where each pixel of the MODIS stack belongs to a cluster (Figure 13).

The next step was to analyze the graphics of each cluster, along with the location of the pixels that belong to each cluster. As mentioned earlier, each LULC has a distinct pattern of evolution of the EVI index during the season. Considering this, we identify the clusters that have an average signature similar to a Gaussian function and identify in which areas those pixels are located (agriculture areas and if they are in dispersed or concentrated groups). Finally, the categories that are considered crops were chosen. In 2014-15 season, clusters 1, 5 and 8, have signatures that correspond to agricultural crop, and their pixels are located in agriculture areas of Uruguay. Additionally, the time of the year in which the minimum and maximum values were registered was analyzed: the minimum corresponding to the date where agricultural crops are sown, and the maximum value, where the agricultural crops are typically in anthesis. The signature patterns of other clusters such as $2,3,4,6,7$ and 9 , do not correspond to agricultural crop signatures.

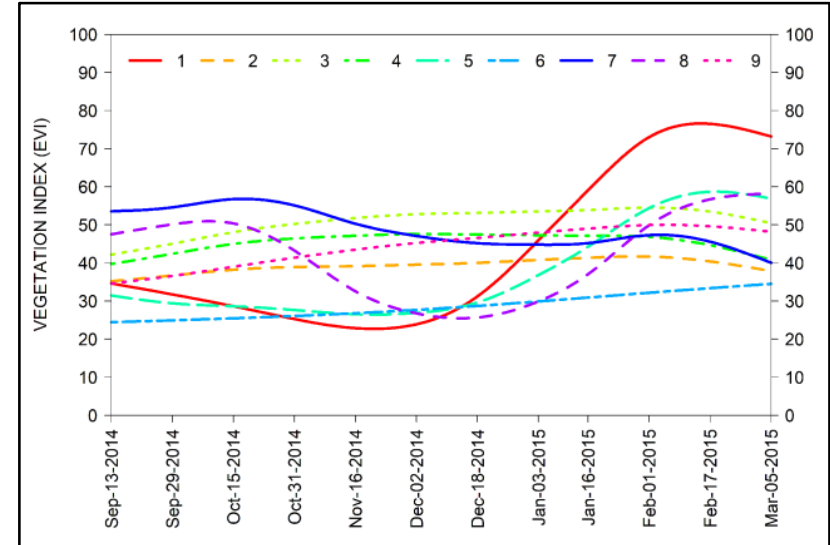

Figure 8. Average EVI phenological firms of clusters.

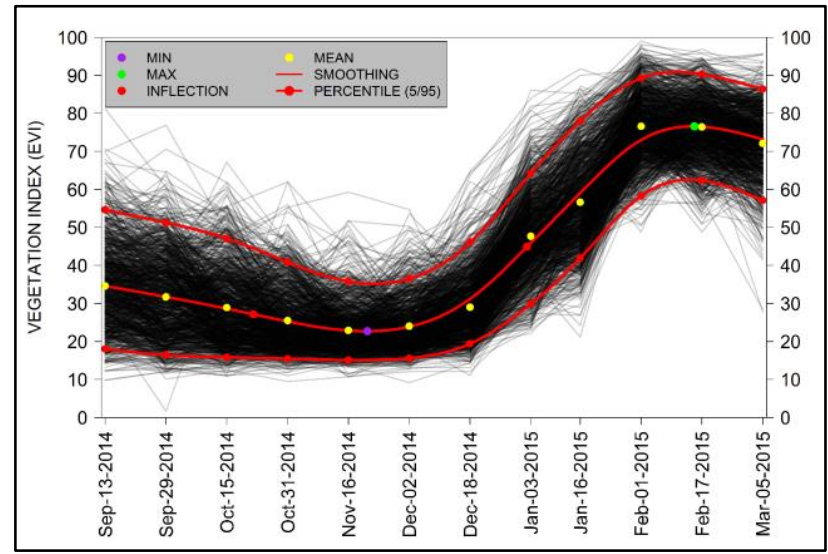

Figure 9. Chart of cluster 1.

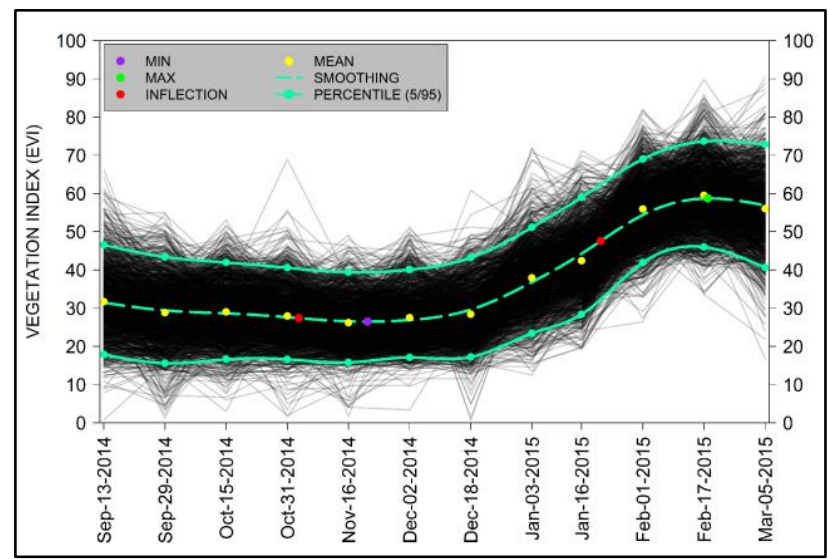

Figure 10. Chart of cluster 5 . 


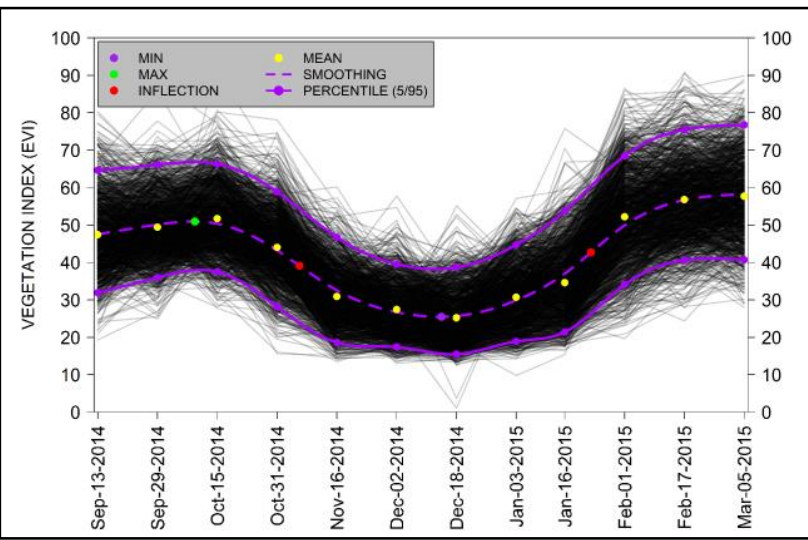

Figure 11. Chart of cluster 8 .

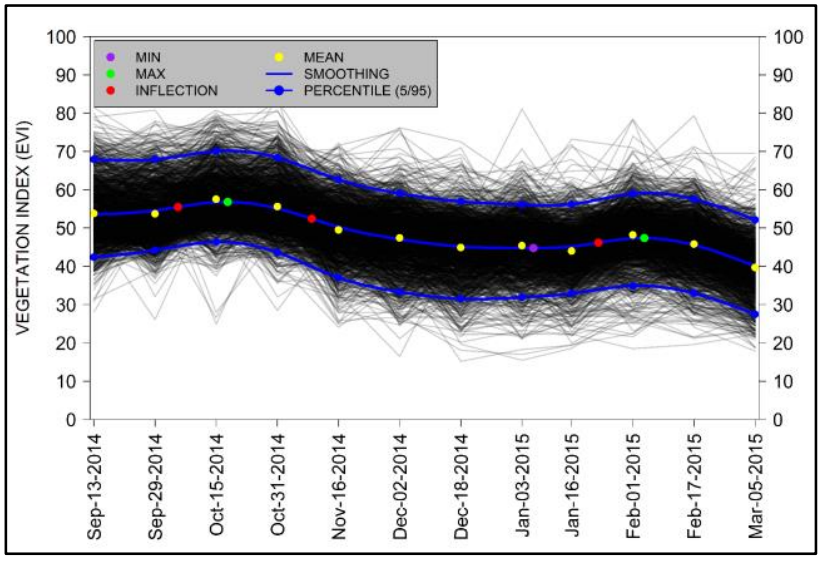

Figure 12. Chart of cluster 7.

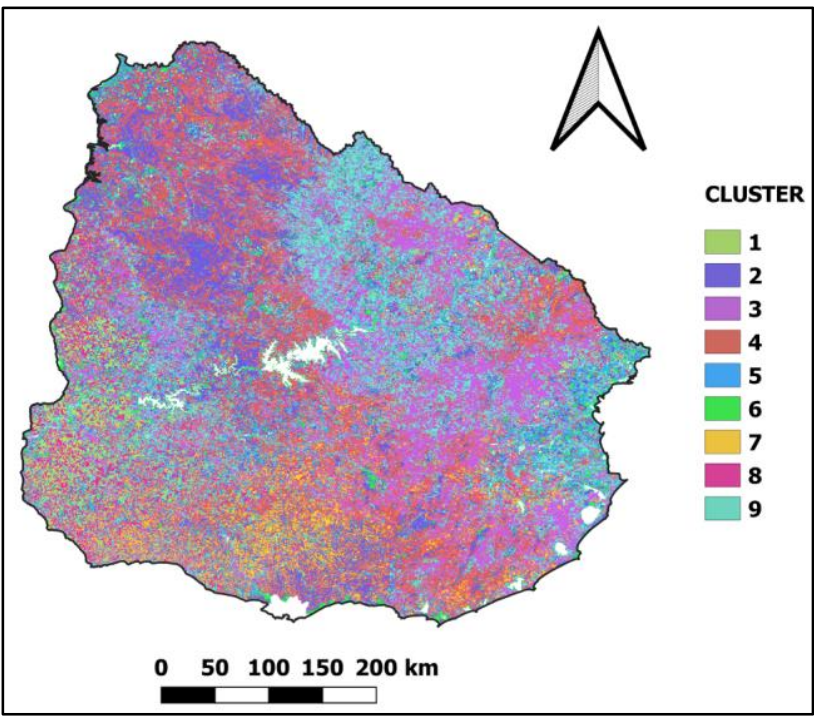

Figure 13. Map of clusters.

After selecting the clusters that have the crop pattern, the final binary map of crops/non-crops was generated (Figure 14) and the total crop area was estimated. According to our map, an area of 2,336,525 hectares was estimated, while the official areas reported was $1,667,400$ hectares. One possible explanation of this difference is the satellite image used, which has a pixel of 250 meters, equivalent to 6.25 hectares (medium resolution pixel). Pixels classified as crops have different degrees of purity, some are pure crops, and others, in different grades, include non-crop, such as: drainage areas, discard areas and other uses.

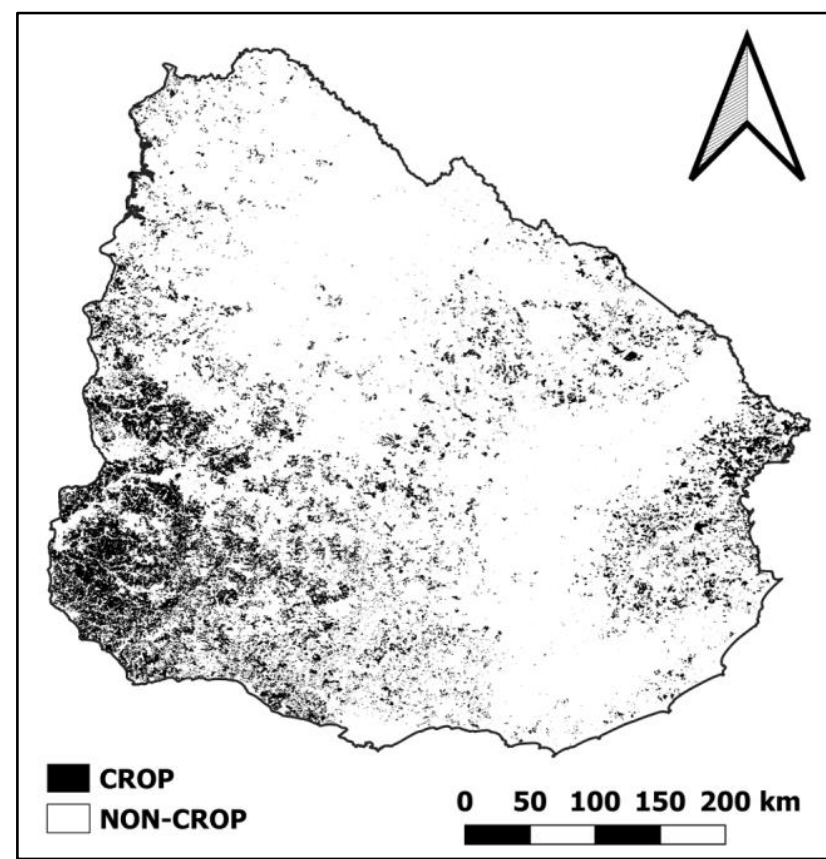

Figure 14. Final map of crops/non-crops.

Validation was performed, a confusion matrix was constructed, and the performance metrics were calculated: general accuracy, balanced accuracy, kappa index, producer's and user's accuracy, and F-measure.

Validation results are shown in Tables 2 and 3. Analyzing the performance metrics data, the overall accuracy is very high, with a value of $95.8 \%$. It is worth to mention that ground truth points are unbalanced, with over 4,000 points of non-crop and 900 of crop. This affects the calculation of general accuracy, being greatly influenced by the majority class. To correct the unbalance, the balanced accuracy, which overcomes this problem, was calculated considering the true positive rate and the true negative rate (Brodersen, Ong, Stephan, \& Buhmann, 2010).

The value of the Kappa index is high (85.6) as is the value of Fmeasure (88.1). If the confusion matrix is considered and each land use is analyzed, it is observed that for crops and non-crops the user's accuracy is greater than $91 \%$, being higher for noncrops. About the producer's accuracy, crops have a lower value than non-crops, but are higher than $85.1 \%$. It was also observed that the omission error for crops is $14.9 \%$ (100-85.1\%), being greater than the omission error for non-crops, and greater than the commission error for crops and non-crops. About the user's accuracy data for crops, the commission error is $8.7 \%$ (100-91.3). If we consider that the estimated area was $2,336,525$ hectares, this is an overestimation of 210,287 hectares, so if this error is discounted to the estimated crop area, it would be reduced to $2,126,237$ hectares. It is also important to mention that the omission error for crops are $14.9 \%$, being twice the commission error, which has a compensation effect on the commission error committed. 


\begin{tabular}{|c|r|r|r|r|}
\hline \multirow{2}{*}{$\begin{array}{c}\text { CLASSIFIED } \\
\text { DATA }\end{array}$} & \multicolumn{2}{|c|}{$\begin{array}{c}\text { REFERENCED } \\
\text { DATA }\end{array}$} & \multirow{2}{*}{ TOTAL } & $\begin{array}{c}\text { USER'S } \\
\text { ACCURACY }\end{array}$ \\
\cline { 2 - 4 } & CROP & $\begin{array}{c}\text { NON- } \\
\text { CROP }\end{array}$ & & 91.3 \\
\hline CROP & 818 & 78 & 896 & 96.8 \\
\hline NON-CROP & 143 & 4,278 & 4,421 & \\
\hline TOTAL & 961 & 4,356 & 5,317 & \\
\hline $\begin{array}{c}\text { PRODUCER'S } \\
\text { ACCURACY }\end{array}$ & 85.1 & 98.2 & \\
& \multicolumn{3}{|c}{ Table 2. Confusion matrix. }
\end{tabular}

\begin{tabular}{|c|c|}
\hline $\begin{array}{c}\text { PERFORMANCE } \\
\text { METRIC }\end{array}$ & $\%$ \\
\hline GENERAL ACCURACY & 95.8 \\
\hline $\begin{array}{c}\text { BALANCED } \\
\text { ACCURACY }\end{array}$ & 91.7 \\
\hline KAPPA INDEX & 85.6 \\
\hline F-MEASURE & 88.1 \\
\hline
\end{tabular}

Table 3. Performance indexes.

\section{CONCLUSIONS}

The method presented in this paper is a possible and fast tool for mapping agricultural areas during the season, without the need for ground truth data. This is achieved by combining: the analysis of time series of vegetation indices (EVI); unsupervised machine learning algorithms (k-means); smoothing techniques; derivative analysis; and expert knowledge. The results found, when compared with ground truth points, have a good performance considering different metrics, obtaining a general accuracy of $95.8 \%$, and user accuracy values above $90 \%$. If the estimated area of crops is considered, it is higher than the official statistics. This can be explained by the resolution of the satellite images used and an overestimation error close to $10 \%$.

The methodology attempts to discriminate non-agriculture from agriculture areas, but does not identify different crops, such as soybean or corn.

This methodology implies that a user must define, based on the average signatures for each cluster and the distribution of the pixels in the territory, which classes correspond to crops. This implies subjectivity that depends on the user, so two different users may not consider the same classes as crops.

For future work, it is necessary to explore satellites of higher spatial resolution such as Landsat 8 and Sentinel 2. It is also necessary to explore the possibility of discriminating between different crops (corn, soybeans, rice) by combining both optical and SAR satellites, such as the Sentinel 1, and combine the method with ground truth data to generate a more robust model.

\section{REFERENCES}

Bendini, H., Sanches, I. D., Körting, T. S., Fonseca, L. M. G., Luiz, A. J. B., \& Formaggio, A. R. (2016). USING LANDSAT 8 IMAGE TIME SERIES FOR CROP MAPPING IN A REGION OF CERRADO, BRAZIL. ISPRS - International Archives of the Photogrammetry, Remote Sensing and Spatial Information Sciences, $\quad$ XLI-B8(July), 845-850. https://doi.org/10.5194/isprsarchives-XLI-B8-845-2016
Brodersen, K. H., Ong, C. S., Stephan, K. E., \& Buhmann, J. M. (2010). The Balanced Accuracy and Its Posterior Distribution. En 2010 20th International Conference on Pattern Recognition (pp. 3121-3124). IEEE. https://doi.org/10.1109/ICPR.2010.764

Chatziantoniou, A., Psomiadis, E., \& Petropoulos, G. (2017). CoOrbital Sentinel 1 and 2 for LULC Mapping with Emphasis on Wetlands in a Mediterranean Setting Based on Machine $\begin{array}{llll}\text { Learning. Remote Sensing, } & \text { 9(12), } & \end{array}$ https://doi.org/10.3390/rs9121259

Fontana, D. C., Pinto, D. G., Junges, A. H., \& Bremm, C. (2015). Using temporal NDVI/MODIS profiles for inferences on the crop soybean calendar. Bragantia, 74(3), 350-358. https://doi.org/10.1590/1678-4499.0439

Huete, A., Didan, K., Miura, T., Rodriguez, E., Gao, X., \& Ferreira, L. (2002). Overview of the radiometric and biophysical performance of the MODIS vegetation indices. Remote Sensing of Environment, 83(1-2), 195-213. https://doi.org/10.1016/S0034-4257(02)00096-2

Johnson, D. (2010). A 5-year analysis of crop phenologies from the United States Heartland (Invited). AGU Fall Meeting Abstracts.

Kodinariya, T. M., \& Makwana, P. R. (2013). Review on determining number of Cluster in K-Means Clustering. International Journal, 1(6), 90-95.

MGAP-DIEA. (2016). Anuario Estadístico de DIEA 2016. Recuperado de http://www.mgap.gub.uy/unidadorganizativa/oficina-de-programacion-y-politicas-

agropecuarias/publicaciones/anuarios-diea/anuario2016

NASA-Earth Observatory. (2000). Measuring Vegetation (NDVI \& EVI). Recuperado 29 de noviembre de 2019, de https://earthobservatory.nasa.gov/features/MeasuringVegetation

Pollock, D. S. G. (1999). Smoothing with Cubic Splines. En Handbook of Time Series Analysis, Signal Processing, and Dynamics (pp. 293-322). Elsevier. https://doi.org/10.1016/B978012560990-6/50013-0

Rekik, A., Zribi, M., Hamida, A. B., \& Benjelloun, M. (2009). An optimal unsupervised satellite image segmentation approach based on Pearson system and k-Means Clustering Algorithm Initialization. World Academy of Science, Engineering and Technology, 35(11), 2181-2188

Salomonson, V. V., Barnes, W., \& Masuoka, E. J. (2006). Introduction to MODIS and an Overview of Associated Activities. En Earth Science Satellite Remote Sensing (Vol. 1, pp. 12-32). Berlin, Heidelberg: Springer Berlin Heidelberg. https://doi.org/10.1007/978-3-540-37293-6_2

Wardlow, B. D., \& Egbert, S. L. (2010). A comparison of MODIS 250-m EVI and NDVI data for crop mapping: a case study for southwest Kansas. International Journal of Remote Sensing, 31(3), https://doi.org/10.1080/01431160902897858 